\title{
Neuro-oncogenesis and the adult human sub- ventricular zone in high grade glioma
}

\author{
Sara G. M. Piccirillo
}

John van Geest Centre for Brain Repair, Department of Clinical Neurosciences, University of Cambridge, Cambridge, CB2 OPY, UK.

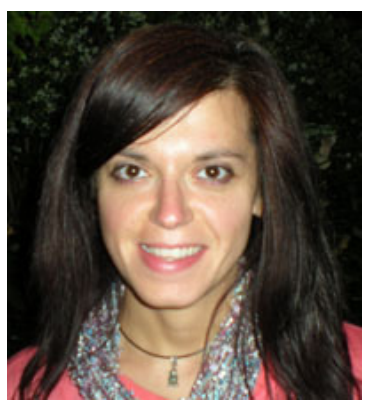

Dr. Sara G. M. Piccirillo graduated from the University of Milan in Medical Biotechnology in 2003 and gained her Ph.D. in Translational and Molecular Medicine at the University of Milan-Bicocca in 2008. Dr. Piccirillo is currently the Research Associate at the Department of Clinical Neurosciences of Cambridge University in UK. Since 2014, she is also the Visiting Senior Scientist at the University of Texas Southwestern Medical Center in Dallas in USA.

The last fifteen years have seen the application of the cancer stem cell hypothesis to tumors of the central nervous system, in particular to high grade glioma (HGG), the most aggressive and common brain cancer in adults. Seminal studies have shown that cancer stem cells (alternatively named tumor-initiating cells) are capable of self-renew and multipotency, similar to their normal counterpart. More importantly they give rise to tumors that closely mimic the phenotype and genotype of human HGG. The identification of neurogenic niches in adult rodent and human brain has further reinforced the hypothesis that HGG might derive from the malignant transformation occurring in these areas, especially in the sub-ventricular zone (SVZ), the largest and most well characterised stem cell niche. Following from evidence of animal model studies supporting this hypothesis, recently we investigated the role of the SVZ in neuro-oncogenesis using tissue material derived from HGG patients. We also described response to conventional chemo-therapies of cancer stem cells isolated from the SVZ and the tumor mass ( $T$ ) of the same patients and reconstructed tumor evolution. In this review, such findings will be discussed in the context of the current literature on the biology of the SVZ in the normal and disease brain.

Key words: High grade glioma; tumor-initiating cells; sub-ventricular zone; tumor development

\section{INTRODUCTION}

High grade glioma (HGG) are aggressive and lethal brain tumors whose prognosis remains dismal despite advances in neurosurgical techniques and combination of radio- and chemo-therapy. The recent years have seen two major directions of investigation: firstly, the evidence from stem cell biology showing that cancer stem-like populations exist in HGG and other brain

Corresponding Author: Dr. Sara G. M. Piccirillo, John van Geest Centre for Brain Repair, Department of Clinical Neurosciences, University of Cambridge, Cambridge, CB2 OPY, UK. E-mail: sara.piccirillo@gmail.com

\begin{tabular}{|l|l|}
\hline \multicolumn{2}{|c|}{ Access this article online } \\
\hline Quick Response Code: & Website: \\
\hline & www.nnjournal.net \\
\hline
\end{tabular}

tumors and secondly, the application of high-resolution genomics to study HGG genetic heterogeneity. However, the existence of cancer stem cells in tumors does not prove per se that the disease originates from normal stem cells.

In the brain, the sub-ventricular zone (SVZ) is a germinal niche where neurogenesis persists throughout adulthood. In the last twenty years, seminal studies have described the cellular organisation and functional properties of this niche, mainly composed of neural stem, precursor cells and migrating neuroblasts. Given

This is an open access article distributed under the terms of the Creative Commons Attribution-NonCommercial-ShareAlike 3.0 License, which allows others to remix, tweak, and build upon the work non-commercially, as long as the author is credited and the new creations are licensed under the identical terms.

For reprints contact: service@oaepublish.com

Cite this article as: Piccirillo SGM. Neuro-oncogenesis and the adult

human sub-ventricular zone in high grade glioma. Neuroimmunol

Neuroinflammation 2016;3:20-6.

Received: 15-09-2015; Accepted: 30-11-2015 
the capacity of stem cells to self-renew and generate differentiating cells while also maintaining their pool, it has been proposed that SVZ stem cells could play a role in tumorigenesis. This hypothesis has been supported by studies using genetically-engineered animal models where the key genetic alterations of HGG occur only in neural stem/precursor cells of the SVZ.

The advent of high-resolution genomic techniques gave us the unique opportunity to overcome the challenges associated with studies in the human brain of HGG where only a small amount of tumor tissue is available and longitudinal studies to assess tumor development are not possible. We developed a real-time fluorescence-guidedtiple-sampling (FGMS) strategy based on 5-aminolevulinic acid to identify cancer stem cells in different tumor regions ${ }^{[1]}$ and we used this approach to describe the extent of spatial genetic intra- tumor heterogeneity in $\mathrm{HGG}^{[1,2]}$ and to reconstruct tumorigenesis. ${ }^{[2]}$ In parallel, we derived cancer stem cells from the tumor mass and the SVZ of the same patients and we showed that drug-resistant cells are present in this niche. ${ }^{[3]}$ These findings have implications for the development of new therapeutic approaches targeting the SVZ.

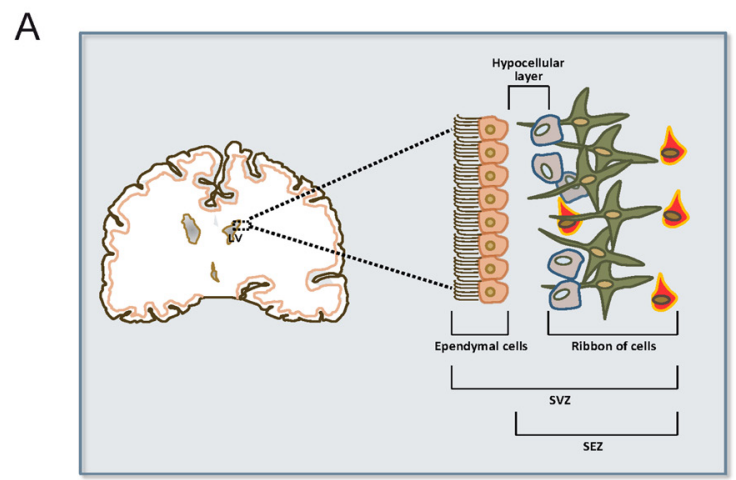

B
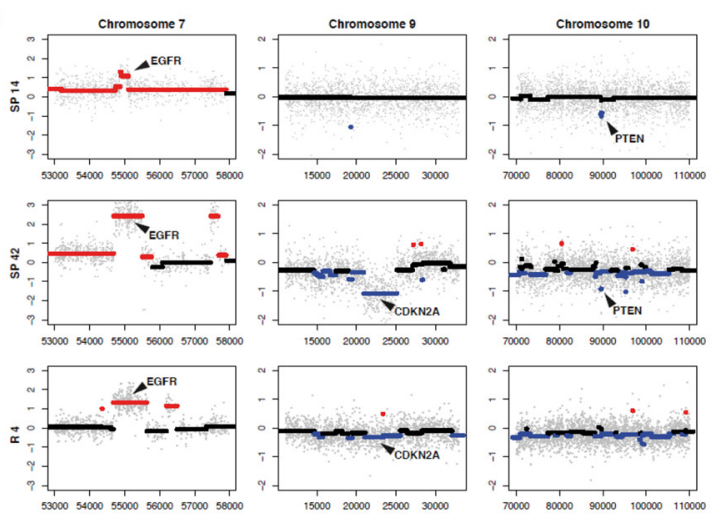

Figure 1: The anatomy of SVZ and the genetic alterations in HGG patients. A: Anatomical structure of the human brain SEZ and SVZ; B: copy number aberrations of three SVZ samples from different patients share hallmarks of HGG such as amplification of EGFR and loss/deletion of PTEN. SP42 and R4 display also loss of CDKN2A, another hallmark of the disease. SP14 also exhibits amplification of AKT3 whereas SP42 shows amplification of CDK6 and MET as well. This clearly confirms the aberrant nature of SVZ cells. HGG: high grade glioma; SEZ: sub-ependymal zone; SVZ: sub-ventricular zone

\section{THE SVZ IN THE ADULT HUMAN BRAIN}

The identification of neurogenic niches in rodents ${ }^{[4]}$ has challenged the long-standing notion that the mammalian brain was a quiescent organ characterized by lack of neurogenesis postnatally. ${ }^{[5]}$ In the adult mammalian brain, neurogenesis occurs in 2 germinal regions: the SVZ[6] and the subgranular layer (SGL) of the dentate gyrus of the hippocampus. ${ }^{[7]}$ Several works on the cellular organisation of the SVZ in rodents have revealed the existence of neural stem cells that express the astrocytic marker glial fibrillary acidic protein (GFAP) and give rise to neurons. When compared to the SGL, the SVZ represents the most abundant source of neurons..$^{[8-11]}$ More recently, studies on the adult human brain have shown that the SVZ retains the same functional properties of the rodent brain, but the GFAP+ve cells are organised in a ribbon. ${ }^{[12,13]}$ However, important differences exist between the human and rodent SVZ: (1) in humans, the SVZ is positioned in the wall of the lateral ventricles and is characterized by 4 layers. SVZ astrocytes are organised in ribbons separated from the ependymal layer by a hypocellular gap, that is a reminiscence of the neuronal formation and migration occurring at embryonic stages ${ }^{[14]}$ [Figure 1]. Interestingly, the terms SVZ and SEZ have been used interchangeably, however they describe specifically these layers with the inclusion or not of the ependymal layer [Figure 1]; (2) the number of actively proliferating cells in human SVZ is very low in comparison to rodents; ${ }^{[12,15]}$ and (3) the evidence of the existence of neural stem cells in vivo is still missing in humans, whereas it is well established in rodents.

Accumulating evidence points out to the influence of pathological conditions on neurogenesis. These include infections, inflammations, stroke, epilepsy, tumors and neurodegenerative disorders. ${ }^{[16,17]}$ For instance, in Huntington's disease an increase in cell proliferation and neurogenesis occur in the SVZ of disease brains. ${ }^{[18]}$ Extending our understanding of the biology of the human SVZ might lead to the identification of novel therapeutic interventions against the large spectrum of diseases affecting the brain.

\section{THE SVZ AS INFLAMMATORY RESERVOIR}

In HGG, the onset of malignant transformation can be seen as a traumatic event that can initiate inflammation. This can then persist during the subsequent phases of tumor growth: promotion and progression. ${ }^{[19]}$ Inflammatory cells, particularly tumor-associated macrophages and microglia, are abundant in HGG and pro-inflammatory genes are overexpressed in the tumor core. ${ }^{[20,21]}$ Most importantly, in HGG inflammation promotes radioresistance. ${ }^{[22]}$ However, so far no study 
has investigated the presence and role of inflammatory cells in the SVZ of brain tumor patients.

It has been shown that inflammatory processes involving interleukin-6 (IL-6) are initiated after neonatal CNS after injury and that both IL-6 and another member of the same cytokine family, i.e. leukemia inhibitory factor, contribute to the expansion of neural stem and progenitor cells in the SVZ after injury ${ }^{[2,23]}$ by activating the JAK/STAT pathway. ${ }^{[24]}$ Despite the high expression of IL-6 in HGG and its promotion of tumor growth ${ }^{[25]}$ and invasion, ${ }^{[26]}$ the role of this cytokine is not fully understood. In a mouse model of astrocytomas with inactivation of the IL- 6 gene locus, tumor formation is suppressed suggesting that IL-6 is required for glioma growth. ${ }^{[27]}$ Additional studies are required to elucidate the functional role of IL- 6 in the SVZ of HGG patients. This might extend our knowledge about its role in promoting malignancy and sustaining neural stem cell self-renewal.

\section{THE SVZ AND THE CANCER STEM CELL HYPOTHESIS}

The idea that cancers derive from stem cells is not entirely new. ${ }^{[28]}$ In recent years evidence supporting this concept has been provided by several works on non-solid and solid cancers. Intriguingly, the concept of a stem cell hierarchy inside a tumor found confirmation in several pathologies, from leukaemia to solid cancers (i.e. breast, brain, colon cancers) ${ }^{[29,30]}$ with the hematopoietic system providing the best example in both chronic myeloid leukaemia and multiple myeloma. ${ }^{[31]}$

However, the initial evidence for the existence of cancer stem cells in several tumors has been followed by the consistent observation that these cells hijack functional properties of normal stem cells. In particular, it has been thought that virtually all cancer cell lines available can be turned into cancer stem cells by changing the growth medium and by exposing them to mitogenic stimuli. More importantly, the functional similarities with normal stem cells has also led to speculate that if cancer cells resemble stem cell features then the tumor itself might originate from the malignant transformation of normal stem cells of that particular tissue, therefore cancer stem cells might represent the tumor "cell of origin". However, "cancer stem cell" and "cell of origin" represent two different concepts ${ }^{[32]}$ that are often confused and used interchangeably.

In HGG, there is evidence that the tumor derives from stem/precursor cells in genetically-engineered animal models of the disease (see next section "The SVZ as an oncogenic niche"). Histological studies on HGG patients revealed a mixture of cell morphologies including virtually all the spectrum of differentiating cells, from highly immature ${ }^{[33,34]}$ to terminally differentiated cells. ${ }^{[35,36]}$ This has further suggested that a stem cell hierarchy might operate in HGG and might be responsible for its highly heterogeneous phenotype. ${ }^{[3]}$

However, more recent studies have pointed out that the capacity of tumor cells to mimic the functional properties of stem cells is a "plastic" process that can be influenced by extrinsic factors (for instance, a more permissive microenvironment characterized by high immunosuppression ${ }^{[37,38]}$ ) or by instrinsic factors (for instance, transcription factor that can induce a stem cell transcriptional program in tumor cells ${ }^{[39]}$ ), thus suggesting that cancer stem cells are the result of an aberrant program of cell plasticity. ${ }^{[00]}$

\section{THE SVZ AS AN ONCOGENIC NICHE}

The importance of the SVZ as a potential oncogenic niche stems from an initial study in the 40s' suggesting that brain tumors with ventricular walls contact might originate from the embryonic rests present in the SVZ ${ }^{[41]}$ This was followed by studies in the 60s' showing that mitosis occurs in the sub-ependymal layer of rodent and primate brain ${ }^{[5,42]}$ and in the $70 \mathrm{~s}^{\text {' }}$ with the intraventricular injections of oncogenic viruses ${ }^{[43,44]}$ More recently, other studies took advantage of the development of genetically-modified viruses and animal models. Interestingly, in mice it was initially shown that undifferentiated (precursor) cells can be more easily transformed when compared to cells that are terminally differentiated, ${ }^{[45,46]}$ thus corroborating the hypothesis that neural stem/precursor cells might represent the target of malignant transformation. In addition to the above findings, a subsequent study comparing cultures of astrocytes vs. neurosphere precursor cells has shown that dedifferentiation of astrocytes (promoted by EGFR activation) makes these cells susceptible to malignant transformation similarly to neural stem cells, by combining loss of critical tumor suppressors, i.e. p16Ink4a/p19Arf. ${ }^{[47]}$

Following the characterization of the adult brain SVZ as stem cell niche in rodents and humans ${ }^{[8,12,48]}$ and the identification of "cancer stem cells", ${ }^{[49]}$ animal models have been extensively developed in order to understand if the SVZ can be a source of brain tumors. ${ }^{[31]}$

In HGG, it has been shown that neurogenic regions are susceptible to malignant transformation, in particular following stereotactic infusion of growth factors, such as PDGF, in the SVZ ${ }^{[50,51]}$ Similarly, using geneticallyengineered mouse models, it has also been demostrated that HGG can be driven by tumor suppressor inactivation in neural stem/progenitor cells $s^{[2,53]}$ and that a subpopulation of stem-like/Nestin(+ve) cells is 
responsible for tumor re-initiation following chemotherapy. ${ }^{[54]}$ In support of these findings it was also noted that p53 mutations preferentially occur in the SVZ. ${ }^{[5]}$

Collectively, these results raise the question on whether cancer stem cells directly derive from SVZ stem cells. Although mouse model studies have indicated that this is the case, these findings have been severely hampered by a limited representation of the aberrant genetic landscape of HGG and the use of markers that poorly discriminate between stem cells and precursor cells. ${ }^{[32]}$ More recently, the same question has been addressed by using a transgenic cell-labelling system known as mosaic analysis with double markers. ${ }^{[56]}$ Using this model, it has been proposed that the cells of origin in HGG are oligodendrocyte precursor cells, thus challenging the notion that HGG may originate from transformation and expansion of the neural stem cell pool.

Although the debate about the cell of origin in HGG is still open, the above studies have helped define the potential targets of malignant transformation that

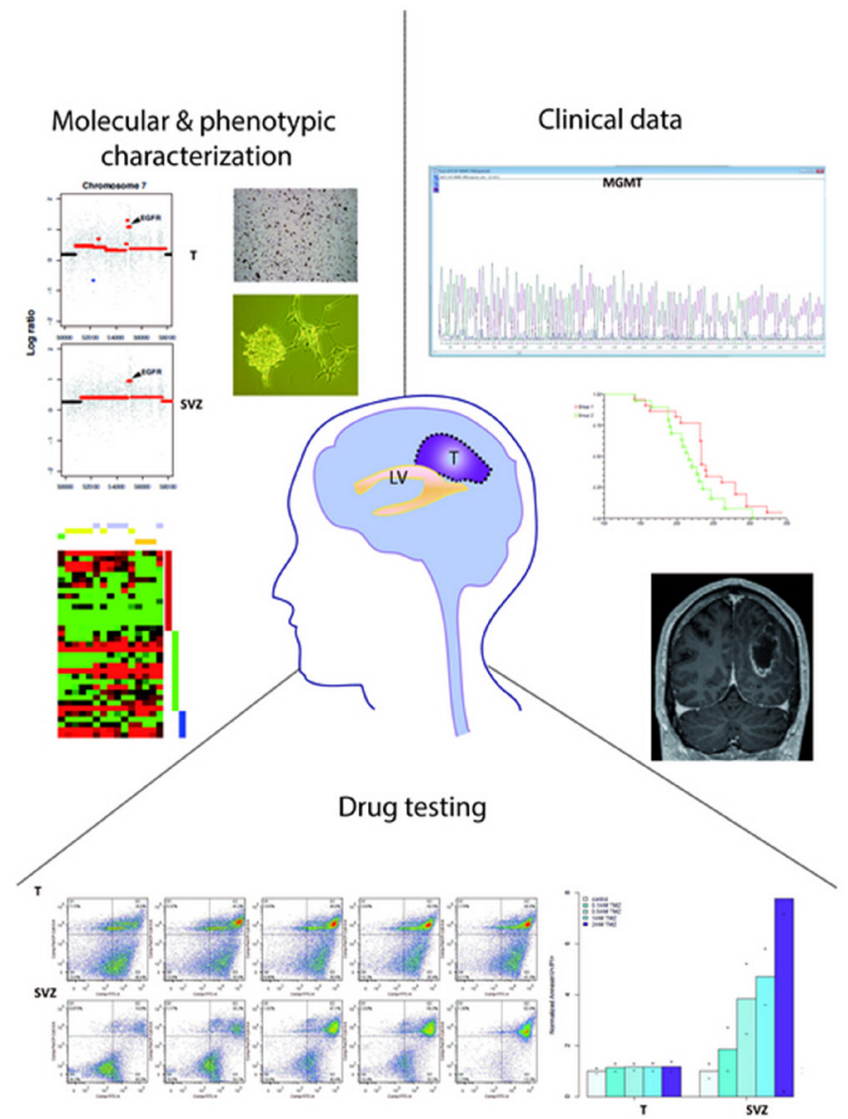

Figure 2: Drug treatments of cancer stem cells derived from SVZ and T combined with molecular and phenotypic characterization of corresponding tissues can help classify HGG patients and develop personalized therapeutic approaches. A better understanding of drug resistance can be achieved by a systematic comparison of drug screening analyses between cancer stem cells isolated from the SVZ and T of the same HGG patient. This will be integrated with molecular profiling of the matched SVZ and T tissues, clinical data and the phenotypic characterization of the derived cells. This approach has the potentia to impact on clinical decisions as the molecular/phenotypic characterization and phylogenetic reconstruction may allow a personalized therapeutic approach based on a better understanding of tumor heterogeneity and potentially may lead to the identification of novel targets in the SVZ and in the T. LV: lateral ventricle; T: tumor mass; HGG: high grade glioma; SVZ: sub-ventricular zone can be further investigated to elucidate the process of oncogenesis in HGG patients. The limited availability of tissue samples and the clinical complex scenario at the time of surgery make it difficult to reconstruct the initial steps of tumor development and alternative methods are needed. Given the critical functional role of the SVZ in the adult human brain, it has been speculated that this niche might play a role in neurooncogenesis. This has been the focus of our recent study on HGG patients. ${ }^{[3]}$

\section{THE SVZ AS A SOURCE OF TUMOR CELLS IN HGG PATIENTS}

The identification of cancer stem cells from human HGG has represented a novel tool to develop therapeutic strategies $^{[57,58]}$ and these cells have been proposed as a model that more closely represents the human disease. ${ }^{[59]}$ We took advantage of these findings to objectively interrogate primary HGG in humans using a neurosurgical techniques based on FGMS. In the clinic fluorescence-guided resection has resulted in enhanced cytoreduction and improved progression-free survival in patients in a randomized Phase III trial. ${ }^{[60]}$ We have adapted this technology to allow the objective identification of tumor tissue based on combining fluorescence emission and neuroanatomical landmarks and we have recently demonstrated that this technique can be successfully employed to characterize cancer stem cells derived from fluorescent and non-fluorescent material in HGG patients. ${ }^{[1]}$

Quite unexpectedly, we observed for the first time that fluorescent material is present in the SVZ of 42 out of 65 HGG patients who underwent surgery using fluorescence-guided resection and we isolated tissue from the tumor mass and the SVZ. Using these samples we reported that the SVZ contains malignant cells that contribute to tumor growth. ${ }^{[3]}$ This has never been demonstrated in humans, but similar observations have been reported in mouse models of HGG. ${ }^{[46,53-55,61]}$

Importantly, the phylogenetic relationship between SVZ and tumor in these patients identifies the SVZ as a reservoir of tumor cells (either early tumor clones or late-emergent clones that develop during HGG growth) that need to be therapeutically targeted. Thus, we investigated responses to chemo-therapeutic agents using cancer stem cells from SVZ and T of the same patients. Surprisingly, we found that such cells respond differently to therapies, which represent the standard of care for HGG patients. Our data also suggest that a large fraction of cells is resistant to chemo-therapy even at supra-maximal doses ${ }^{[3]}$ providing a possible explanation for the treatment failure seen in HGG patients. 
In this context, cancer stem cells isolated from SVZ could be used for drug screening to develop new therapeutic strategies aimed at understanding their mechanisms of resistance [Figure 2]. Targeting the SVZ will require extensive characterization of the phenotype(s) of these cells as well as their studies to assess the response to radiation. Interestingly, it has been shown that irradiation of the SVZ in HGG patients improves progression-free survival. ${ }^{[62]}$

The involvement of the SVZ in HGG also prompt to the need of classifying tumors according to their location in the brain and integrating these data with molecular and phenotypic analysis and clinical information [Figure 2]. A previous work showed that HGG involving the SVZ give rise to recurrences far from the primary tumor site, contributing to the hypothesis that this is due to migrating neural precursors. ${ }^{\left[{ }^{33]}\right.}$ However, another study suggested that there is no evidence of a "stem cell signature" in HGG with involvement of SVZ in comparison to those with no involvement of this region. ${ }^{[64]}$ This might be reconciled considering that, as suggested by animal model studies, HGG originated in the SVZ grow along white matter tracts and macroscopically do not show involvement of the SVZ. ${ }^{[52]}$ The combination of studies on the adult human SVZ in HGG patients and animal models might shed new light on the functional role of this region in neuro-oncogenesis.

\section{CONCLUSION}

With the life expectancy reduced of twenty years, on average, brain tumors represent the most lethal cancer in adults. ${ }^{[6]}$ Among these, HGG is the most aggressive form and among glioma has the poorest prognosis. The function role of the largest neurogenic niche in the brain (i.e. the SVZ) and its presence in the adult human brain, raised the possibility that this area might play a role in the oncogenic process leading to HGG.

Our study revealed that two types of evolutionary trajectories can be observed in patients: the first sees the SVZ playing a role in the growth of the tumor as early clone, whereas in the second the SVZ represents a late emerging clone that suggests infiltration of this area following tumor growth. These results are extremely important as they provide insights about the cell of origin of human HGG but also might impact on treatment strategies. In this respect, our drug treatment data clearly show distinct patterns of response in the same HGG and the existence of chemo-resistant tumor cells in the SVZ. However, the response of SVZ tumor cells to radiation is still to be explored. Interestingly, previous studies have reported that OPC are sensitive to radiation ${ }^{[6]}$ and more recently it has been shown that OPC-like glioma Olig2+ cells respond better to radiation than HGG cells ${ }^{[67]}$ identified by CD44. ${ }^{[68]}$

At the same time, other questions need to be addressed: (1) what is the role of the other well characterized neurogenic region in the adult brain (i.e. the SGZ); could this be also source of neural precursors responsible for initiate HGG and other brain tumors in patients? (2) what are the evolutionary trajectories in those patients where the HGG lies in the cortical mantle and does not show any contact with the SVZ by using FGMS? We have just started to scratch the surface of what seems to be a complicated dynamic process of HGG evolution that involves the SVZ, in addition to more recent publications by $\mathrm{us}^{[69]}$ and others ${ }^{[70]}$ deciphering the genomic architecture of the $\mathrm{T}$. There is hope that these findings and more studies on the role of SVZ in brain tumors might impact on improving patient survival and leading to personalized treatments.

\section{Acknowledgments}

The author is grateful to Mr. M. Locatelli for support and encouragement throughout the preparation of this work.

Financial support and sponsorship

Nil.

\section{Conflicts of interest}

There are no conflicts of interest.

\section{REFERENCES}

1. Piccirillo SG, Dietz S, Madhu B, Griffiths J, Price SJ, Collins VP, Watts C. Fluorescence-guided surgical sampling of glioblastoma identifies phenotypically distinct tumour-initiating cell populations in the tumour mass and margin. Br J Cancer 2012;107:462-8.

2. Sottoriva A, Spiteri I, Piccirillo SG, Touloumis A, Collins VP, Marioni JC, Curtis C, Watts C, Tavare S. Intratumor heterogeneity in human glioblastoma reflects cancer evolutionary dynamics. Proc Natl Acad Sci U S A 2013;110:4009-14

3. Piccirillo SG, Spiteri I, Sottoriva A, Touloumis A, Ber S, Price SJ, Heywood R, Francis NJ, Howarth KD, Collins VP, Venkitaraman AR, Curtis C, Marioni JC, Tavare S, Watts C. Contributions to drug resistance in glioblastoma derived from malignant cells in the subependymal zone. Cancer Res 2015;75:194-202.

4. Alvarez-Buylla A, Lim DA. For the long run: maintaining germinal niches in the adult brain. Neuron 2004;41:683-6.

5. Altman J. Autoradiographic investigation of cell proliferation in the brains of rats and cats. Anat Rec 1963;145:573-91.

6. Alvarez-Buylla A, Garcia-Verdugo JM. Neurogenesis in adult subventricular zone. J Neurosci 2002;22:629-34.

7. Kempermann G. Why new neurons? Possible functions for adult hippocampal neurogenesis. J Neurosci 2002;22:635-8.

8. Doetsch F, Caille I, Lim DA, Garcia-Verdugo JM, Alvarez-Buylla A. Subventricular zone astrocytes are neural stem cells in the adult mammalian brain. Cell 1999;97:703-16.

9. Laywell ED, Rakic P, Kukekov VG, Holland EC, Steindler DA Identification of a multipotent astrocytic stem cell in the immature and adult mouse brain. Proc Natl Acad Sci U S A 2000;97:13883-8.

10. Kim M, Morshead CM. Distinct populations of forebrain neural stem and progenitor cells can be isolated using side-population analysis. $J$ Neurosci 2003;23:10703-9.

11. Garcia AD, Doan NB, Imura T, Bush TG, Sofroniew MV. GFAPexpressing progenitors are the principal source of constitutive neurogenesis in adult mouse forebrain. Nat Neurosci 2004;7:1233- 
41.

12. Sanai N, Tramontin AD, Quinones-Hinojosa A, Barbaro NM, Gupta N, Kunwar S, Lawton MT, McDermott MW, Parsa AT, ManuelGarcia Verdugo J, Berger MS, Alvarez-Buylla A. Unique astrocyte ribbon in adult human brain contains neural stem cells but lacks chain migration. Nature 2004;427:740-4.

13. van den Berge SA, Middeldorp J, Zhang CE, Curtis MA, Leonard BW, Mastroeni D, Voorn P, van de Berg WD, Huitinga I, Hol EM. Longterm quiescent cells in the aged human subventricular neurogenic system specifically express GFAP-delta. Aging Cell 2010;9:313-26.

14. Guerrero-Cazares H, Gonzalez-Perez O, Soriano-Navarro M, Zamora-Berridi G, Garcia-Verdugo JM, Quinones-Hinojosa A. Cytoarchitecture of the lateral ganglionic eminence and rostral extension of the lateral ventricle in the human fetal brain. $J$ Comp Neurol 2011;519:1165-80.

15. Curtis MA, Kam M, Nannmark U, Anderson MF, Axell MZ, Wikkelso C, Holtas S, van Roon-Mom WM, Bjork-Eriksson T, Nordborg C, Frisen J, Dragunow M, Faull RL, Eriksson PS. Human neuroblasts migrate to the olfactory bulb via a lateral ventricular extension. Science 2007;315:1243-9.

16. Danzer SC. Postnatal and adult neurogenesis in the development of human disease. Neuroscientist 2008;14:446-58

17. Curtis MA, Low VF, Faull RL. Neurogenesis and progenitor cells in the adult human brain: a comparison between hippocampal and subventricular progenitor proliferation. Dev Neurobiol 2012;72:9901005.

18. Curtis MA, Penney EB, Pearson AG, van Roon-Mom WM, Butterworth NJ, Dragunow M, Connor B, Faull RL. Increased cell proliferation and neurogenesis in the adult human Huntington's disease brain. Proc Natl Acad Sci U S A 2003;100:9023-7.

19. Ha ET, Antonios JP, Soto H, Prins RM, Yang I, Kasahara N, Liau LM, Kruse CA. Chronic inflammation drives glioma growth: cellular and molecular factors responsible for an immunosuppressive microenvironment. Neuroimmunol Neuroinflammation 2014;1:6676.

20. Charles NA, Holland EC, Gilbertson R, Glass R, Kettenmann H. The brain tumor microenvironment. Glia 2012;60:502-14.

21. Glass R, Synowitz M. CNS macrophages and peripheral myeloid cells in brain tumours. Acta Neuropathol 2014;128:347-62.

22. Covey MV, Levison SW. Leukemia inhibitory factor participates in the expansion of neural stem/progenitors after perinatal hypoxia/ ischemia. Neuroscience 2007;148:501-9.

23. Covey MV, Loporchio D, Buono KD, Levison SW. Opposite effect of inflammation on subventricular zone versus hippocampal precursors in brain injury. Ann Neurol 2011;70:616-26.

24. Bauer S. Cytokine control of adult neural stem cells. Ann N Y Acad Sci 2009;1153:48-56.

25. Wang H, Lathia JD, Wu Q, Wang J, Li Z, Heddleston JM, Eyler CE, Elderbroom J, Gallagher J, Schuschu J, MacSwords J, Cao Y, McLendon RE, Wang XF, Hjelmeland AB, Rich JN. Targeting interleukin 6 signaling suppresses glioma stem cell survival and tumor growth. Stem Cells 2009;27:2393-404.

26. Liu Q, Li G, Li R, Shen J, He Q, Deng L, Zhang C, Zhang J. IL-6 promotion of glioblastoma cell invasion and angiogenesis in U251 and T98G cell lines. J Neurooncol 2010;100:165-76.

27. Weissenberger J, Loeffler S, Kappeler A, Kopf M, Lukes A, Afanasieva TA, Aguzzi A, Weis J. IL-6 is required for glioma development in a mouse model. Oncogene 2004;23:3308-16.

28. Huntly BJ, Gilliland DG. Leukaemia stem cells and the evolution of cancer-stem-cell research. Nat Rev Cancer 2005;5:311-21.

29. Reya T, Morrison SJ, Clarke MF, Weissman IL. Stem cells, cancer, and cancer stem cells. Nature 2001;414:105-11.

30. Piccirillo SG, Vescovi AL. Brain tumour stem cells: possibilities of new therapeutic strategies. Expert Opin Biol Ther 2007;7:1129-35.

31. Sanai N, Alvarez-Buylla A, Berger MS. Neural stem cells and the origin of gliomas. N Engl J Med 2005;353:811-22.

32. Visvader JE. Cells of origin in cancer. Nature 2011;469:314-22.

33. Dahlstrand J, Collins VP, Lendahl U. Expression of the class VI intermediate filament nestin in human central nervous system tumors. Cancer Res 1992;52:5334-41.

34. Tohyama T, Lee VM, Rorke LB, Marvin M, McKay RD, Trojanowski
JQ. Nestin expression in embryonic human neuroepithelium and in human neuroepithelial tumor cells. Lab Invest 1992;66:303-13.

35. Collins VP. Brain tumours: classification and genes. $J$ Neurol Neurosurg Psychiatry 2004;75 Suppl 2:ii2-11.

36. Burger PC, Scheithauser, B. W., Vogel, F. S. Surgical pathology of the nervous system and its cverings 1991;Churchill Livingstone.

37. Quintana E, Shackleton M, Foster HR, Fullen DR, Sabel MS, Johnson TM, Morrison SJ. Phenotypic heterogeneity among tumorigenic melanoma cells from patients that is reversible and not hierarchically organized. Cancer cell 2010;18:510-23.

38. Quintana E, Shackleton M, Sabel MS, Fullen DR, Johnson TM, Morrison SJ. Efficient tumour formation by single human melanoma cells. Nature 2008;456:593-8.

39. Suva ML, Rheinbay E, Gillespie SM, Patel AP, Wakimoto H, Rabkin SD, Riggi N, Chi AS, Cahill DP, Nahed BV, Curry WT, Martuza RL, Rivera MN, Rossetti N, Kasif S, Beik S, Kadri S, Tirosh I, Wortman I, Shalek AK, Rozenblatt-Rosen O, Regev A, Louis DN, Bernstein BE. Reconstructing and reprogramming the tumor-propagating potential of glioblastoma stem-like cells. Cell 2014;157:580-94.

40. Tang DG. Understanding cancer stem cell heterogeneity and plasticity. Cell Res 2012;22:457-72.

41. Globus $\mathrm{JH}$, Kuhlenbeck $\mathrm{H}$. The subependymal plate (matrix) and its relationship to brain tumors of the ependymal type. JNeuropath Exp Neurol 1944;3:1-35.

42. Lewis PD. Mitotic activity in the primate subependymal layer and the genesis of gliomas. Nature 1968;217:974-5

43. Copeland DD, Vogel FS, Bigner DD. The induction of intractranial neoplasms by the inoculation of avian sarcoma virus in perinatal and adult rats. J Neuropathol Exp Neurol 1975;34:340-58.

44. Copeland DD, Bigner DD. The role of the subependymal plate in avian sarcoma virus brain tumor induction: comparison of incipient tumors in neonatal and adult rats. Acta Neuropathol 1977;38:1-6.

45. Holland EC, Hively WP, DePinho RA, Varmus HE. A constitutively active epidermal growth factor receptor cooperates with disruption of $\mathrm{G} 1$ cell-cycle arrest pathways to induce glioma-like lesions in mice. Genes Dev 1998;12:3675-85

46. Holland EC, Celestino J, Dai C, Schaefer L, Sawaya RE, Fuller GN. Combined activation of Ras and Akt in neural progenitors induces glioblastoma formation in mice. Nat Genet 2000;25:55-7.

47. Bachoo RM, Maher EA, Ligon KL, Sharpless NE, Chan SS, You MJ, Tang Y, DeFrances J, Stover E, Weissleder R, Rowitch DH, Louis DN, DePinho RA. Epidermal growth factor receptor and Ink4a/ Arf: convergent mechanisms governing terminal differentiation and transformation along the neural stem cell to astrocyte axis. Cancer Cell 2002;1:269-77.

48. DoetschF,Garcia-VerdugoJM,Alvarez-BuyllaA.Cellularcomposition and three-dimensional organization of the subventricular germinal zone in the adult mammalian brain. J Neurosci 1997;17:5046-61.

49. Piccirillo SGM, Spiteri I. Intratumor heterogeneity and transcriptional profiling in glioblastoma: translational opportunities. Future Neurology 2015;10:369-81.

50. Assanah MC, Bruce JN, Suzuki SO, Chen A, Goldman JE, Canoll P. PDGF stimulates the massive expansion of glial progenitors in the neonatal forebrain. Glia 2009;57:1835-47.

51. Jackson EL, Garcia-Verdugo JM, Gil-Perotin S, Roy M, QuinonesHinojosa A, VandenBerg S, Alvarez-Buylla A. PDGFR alpha-positive $B$ cells are neural stem cells in the adult SVZ that form gliomalike growths in response to increased PDGF signaling. Neuron 2006;51:187-99.

52. Zhu Y, Guignard F, Zhao D, Liu L, Burns DK, Mason RP, Messing A, Parada LF. Early inactivation of p53 tumor suppressor gene cooperating with NF1 loss induces malignant astrocytoma. Cancer Cell 2005;8:119-30.

53. Alcantara Llaguno S, Chen J, Kwon CH, Jackson EL, Li Y, Burns DK, Alvarez-Buylla A, Parada LF. Malignant astrocytomas originate from neural stem/progenitor cells in a somatic tumor suppressor mouse model. Cancer Cell 2009;15:45-56.

54. Chen J, Li Y, Yu TS, McKay RM, Burns DK, Kernie SG, Parada LF. A restricted cell population propagates glioblastoma growth after chemotherapy. Nature 2012;488:522-6.

55. Wang Y, Yang J, Zheng H, Tomasek GJ, Zhang P, McKeever PE, Lee EY, Zhu Y. Expression of mutant p53 proteins implicates a lineage 
relationship between neural stem cells and malignant astrocytic glioma in a murine model. Cancer Cell 2009;15:514-26.

56. Liu C, Sage JC, Miller MR, Verhaak RG, Hippenmeyer S, Vogel H, Foreman O, Bronson RT, Nishiyama A, Luo L, Zong H. Mosaic analysis with double markers reveals tumor cell of origin in glioma. Cell 2011;146:209-21.

57. Piccirillo SG, Reynolds BA, Zanetti N, Lamorte G, Binda E, Broggi G, Brem H, Olivi A, Dimeco F, Vescovi AL. Bone morphogenetic proteins inhibit the tumorigenic potential of human brain tumourinitiating cells. Nature 2006;444:761-5.

58. Fan X, Khaki L, Zhu TS, Soules ME, Talsma CE, Gul N, Koh C, Zhang J, Li YM, Maciaczyk J, Nikkhah G, Dimeco F, Piccirillo S, Vescovi AL, Eberhart CG. NOTCH pathway blockade depletes CD133-positive glioblastoma cells and inhibits growth of tumor neurospheres and xenografts. Stem Cells 2010;28:5-16.

59. Lee J, Kotliarova S, Kotliarov Y, Li A, Su Q, Donin NM, Pastorino S, Purow BW, Christopher N, Zhang W, Park JK, Fine HA. Tumor stem cells derived from glioblastomas cultured in bFGF and EGF more closely mirror the phenotype and genotype of primary tumors than do serum-cultured cell lines. Cancer Cell 2006;9:391-403.

60. Stummer W, Pichlmeier U, Meinel T, Wiestler OD, Zanella F, Reulen HJ. Fluorescence-guided surgery with 5-aminolevulinic acid for resection of malignant glioma: a randomised controlled multicentre phase III trial. The lancet oncology 2006;7:392-401.

61. Zheng H, Ying H, Yan H, Kimmelman AC, Hiller DJ, Chen AJ, Perry SR, Tonon G, Chu GC, Ding Z, Stommel JM, Dunn KL, Wiedemeyer $\mathrm{R}$, You MJ, Brennan C, Wang YA, Ligon KL, Wong WH, Chin L, DePinho RA. p53 and Pten control neural and glioma stem/ progenitor cell renewal and differentiation. Nature 2008;455:1129. 33.

62. Evers P, Lee PP, DeMarco J, Agazaryan N, Sayre JW, Selch M, Pajonk F. Irradiation of the potential cancer stem cell niches in the adult brain improves progression-free survival of patients with malignant glioma. BMC Cancer 2010;10:384.

63. Lim DA, Cha S, Mayo MC, Chen MH, Keles E, VandenBerg S, Berger MS. Relationship of glioblastoma multiforme to neural stem cell regions predicts invasive and multifocal tumor phenotype. Neuro
Oncol 2007;9:424-9

64. Kappadakunnel M, Eskin A, Dong J, Nelson SF, Mischel PS, Liau LM, Ngheimphu P, Lai A, Cloughesy TF, Goldin J, Pope WB. Stem cell associated gene expression in glioblastoma multiforme: relationship to survival and the subventricular zone. J Neurooncol 2010;96:35967.

65. Burnet NG, Jefferies SJ, Benson RJ, Hunt DP, Treasure FP. Years of life lost (YLL) from cancer is an important measure of population burden--and should be considered when allocating research funds. Br J Cancer 2005;92:241-5.

66. Fukuda A, Fukuda H, Jonsson M, Swanpalmer J, Hertzman S, Lannering B, Bjork-Eriksson T, Marky I, Blomgren K. Progenitor cell injury after irradiation to the developing brain can be modulated by mild hypothermia or hyperthermia. J Neurochem 2005;94:1604-19.

67. Bhat KP, Balasubramaniyan V, Vaillant B, Ezhilarasan R, Hummelink K, Hollingsworth F, Wani K, Heathcock L, James JD, Goodman LD, Conroy S, Long L, Lelic N, Wang S, Gumin J, Raj D, Kodama Y, Raghunathan A, Olar A, Joshi K, Pelloski CE, Heimberger A, Kim SH, Cahill DP, Rao G, Den Dunnen WF, Boddeke HW, Phillips HS, Nakano I, Lang FF, Colman H, Sulman EP, Aldape K. Mesenchymal differentiation mediated by NF-kappaB promotes radiation resistance in glioblastoma. Cancer Cell 2013;24:331-46.

68. Jijiwa M, Demir H, Gupta S, Leung C, Joshi K, Orozco N, Huang T, Yildiz VO, Shibahara I, de Jesus JA, Yong WH, Mischel PS, Fernandez S, Kornblum HI, Nakano I. CD44v6 regulates growth of brain tumor stem cells partially through the AKT-mediated pathway. PLoS One 2011;6:e24217.

69. Piccirillo SGM, Colman S, Potter NE, van Delft FW, Lillis S, Carnicer MJ, Kearney L, Watts C, Greaves M. Genetic and functional diversity of propagating cells in glioblastoma. Stem Cell Reports 2015;4:7-15.

70. Kim H, Zheng S, Amini SS, Virk SM, Mikkelsen T, Brat DJ, Grimsby J, Sougnez C, Muller F, Hu J, Sloan AE, Cohen ML, Van Meir EG, Scarpace L, Laird PW, Weinstein JN, Lander ES, Gabriel S, Getz G, Meyerson M, Chin L, Barnholtz-Sloan JS, Verhaak RG. Wholegenome and multisector exome sequencing of primary and posttreatment glioblastoma reveals patterns of tumor evolution. Genome Res 2015;25:316-27. 